\title{
Histological features in pediatric central nervous system tumors with FGFR alterations
}

\author{
Ahmed Gilani, Kurtis Davies, Bette Kleinschmidt-DeMasters \\ University of Colorado Anschutz Medical Campus, United States
}

\begin{abstract}
Introduction: Identification of genetic alterations in central nervous system (CNS) tumors provides diagnostic and prognostic information and allows identification of potential therapeutic targets. Next-generation sequencing (NGS) technologies currently used for molecular testing are costly and remain largely limited to major academic centers or reference labs. Identification of histologic or immunohistochemical correlates for particular molecular alterations can serve as surrogates and can help triage cases for subsequent NGS-based confirmation. Recently, adult IDH-wildtype adult glioblastomas (GBMs) with fibroblast growth factor receptor (FGFR) gene alterations were reported to show palisading monomorphic cells, delicate arcuate vasculature, and microcalcifications. We explored whether pediatric tumors with FGFR fusion also show these histologic features and whether these features could predict the presence of this gene alteration.

Material and methods: We reviewed pediatric CNS tumors with FGFR-fusions to retrospectively determine the presence/absence of the above-mentioned histological features in fusion-positive tumors.

Results: 10 pediatric tumors with FGFR fusions were identified. Pediatric tumors demonstrated histologic and tumor type diversity, with diagnoses of pilocytic/pilomyxoid astrocytoma, pediatric-type oligodendroglioma, anaplastic astrocytoma, polymorphous low-grade neuroepithelial tumor of the young, rosette-forming glioneuronal tumor, and extraventricular neurocytoma.

Conclusions: Pediatric FGFR-fused CNS tumors demonstrate histologic features similar to their adult counterparts but also exhibit significant morphologic variability. As such, this histologic variability prevents the prediction of FGFR fusion and necessitates molecular testing for the identification of this alteration.
\end{abstract}

Key words: FGFR, TACC, polymorphous low-grade neuroepithelial tumor of the young (PLNTY), glioneuronal, astrocytoma, fusion testing, next-generation sequencing.

\section{Introduction}

In 2016, the World Health Organization (WHO) Classification of Central Nervous System (CNS) Tumors adopted an integrative diagnostic approach incorporating molecular parameters into the classification of CNS tumor entities [14]. Molecular char- acteristics are likely to play an even more prominent role in the upcoming WHO classification with the possible introduction of several new categories of tumors defined by their molecular signature. In addition to aiding diagnosis, identification of genetic alterations also provides valuable prognostic infor-

\section{Communicating author}

Ahmed Gilani, MD, PhD, University of Colorado Anschutz Medical Campus, 13123 East 16th Avenue, Box 120, Aurora, CO 80045, United States, e-mail: ahmed.gilani@childrenscolorado.org 
mation and, most importantly, can help in the identification of targeted therapy.

Next-generation sequencing (NGS) technologies are currently the most widely used for identification of molecular alterations in routine clinical practice but require high upfront infrastructure investment and have substantial running costs. The availability of NGS-testing is consequently still largely limited to large academic centers or reference labs. Identification of histologic or immunohistochemical (IHC) correlates can serve as surrogates for molecular alterations and can help triage cases for subsequent NGS-testing in select cases. This strategy has proved useful for IDH-mutant 1p19q-codeleted oligodendroglioma and BRAF V600E-positive epithelioid glioblastoma (GBM), for example [14]. In these tumors, careful histomorphologic examination and IHC studies can reliably select cases likely to harbor the molecular alteration. These can then be confirmed or disproved on targeted molecular testing [14]. Excellent molecular-histologic correlation also exists between $B R A F: K I A A 1549$ fusion and pilocytic astrocytoma and between $M Y B: Q K I$ and angiocentric glioma. Many other tumors, however, show poor molecular-histologic correlation. Hence, for each tumor type, it is important to determine if and to what extent molecular-histological correlation exists. If such a correlation is high, it can assist the pathologist in triaging cases for confirmatory molecular testing [13].

Molecular-histologic correlation was recently demonstrated in a subset of adult GBMs when it was shown that adult IDH-wildtype adult GBMs with fibroblast growth factor receptor (FGFR) gene alterations show palisading monomorphic cells, delicate arcuate vasculature, and microcalcifications [3]. This was confirmed by several subsequent studies [1,2]. Whether FGFR-altered tumors show histomorphologic similarity outside of the adult $I D H$-wildtype group is less clear. In this study, we explore whether the histologic features reported for FGFR-altered $I D H$-wildtype adult GBMs are shared by pediatric tumors with FGFR fusion and if these characteristics can be used to predict FGFR fusions in individual cases.

FGFR signaling regulates a variety of cellular pathways including cell proliferation, differentiation, and survival. FGFRs form a family of four highly conserved transmembrane receptor tyrosine kinases (FGFR1-4), and alterations in 3 FGFR genes (FGFR1/ FGFR2/FGFR3) have been reported in a variety of pediatric and adult tumors [4,7,16,17]. Recently, a subset of adult IDH-wildtype GBMs was found to harbor gene fusion events involving FGFR1/FGFR3 with the transforming acidic coiled-coil (TACC) domains of TACC 1 or TACC 3 genes $[3,5,19]$. Recognition of this alteration carries particular clinical significance as inhibitors of FGFRs have recently been developed and these could represent a promising therapeutic option for patients with FGFR alterations [5]. Studies have shown that inhibitors of kinase activity can block tumor growth in a preclinical model of gliomas with the TACC3:FGFR3 fusion and clinical response has been documented in a few patients [5]. The TACC gene family includes 3 individual genes, including TACC1, TACC2, and TACC3. TACC domains promote dimerization and constitutive activation of FGFR leading to hyperphosphorylation and constitutive activation of the kinase domain promoting oncogenesis [15,19,23].

Characteristic histologic features reported for FGFR3:TACC3 gliomas in adults include a monomorphic population of small tumor cells with ovoid nuclei, perivascular pseudorosettes, microcalcifications, nuclear palisading, and/or an endocrinoid ("chicken-wire") capillary network [3]. All cases show absence of cytoplasmic IDH1 R132H immunostaining, low p53 nuclear immunolabelling and retained nuclear ATRX expression. The most common cytogenetic alterations include: gain of chromosome $7 \mathrm{p} /$ loss of chromosome $10 \mathrm{q}$, absence of EGFR amplification except in rare cases $[3,5,9]$, and frequent CDKN2A homozygous deletion [5,9]. Thus morphology and routine cytogenetic tests can provide clues to the presence of FGFR3 fusions in adult gliomas, the majority of which are GBMs, IDH-wildtype, WHO grade IV [3]. This correlation between histology and the presence of FGFR3:TACC 3 alteration is not perfect and molecular testing still needs to be performed to confirm the fusion. While the vast majority of these tumors feature an FGFR3:TACC3 fusion, rare cases showing FGFR3 fusion with a non-TACC3 gene partner (such as CAMK2A) have also been reported [9].

Various other pediatric and adult tumors have been reported to have FGFR fusions $[4,7,17]$. While a majority of pilocytic astrocytoma (PA) show BRAF fusions or mutations, a small proportion feature FGFR fusions [12,16,18,21]. FGFR1:TACC1 fusion is a frequent event in extraventricular neurocytoma and has been found in up to $60 \%$ of molecularly-defined cases [22] with a smaller proportion of cases 
showing FGFR3:TACC3 alteration [22], as recently reviewed [1]. Similarly, the recently described tumor termed polymorphous low-grade neuroepithelial tumor of the young (PLNTY) also features FGFR2 and FGFR3 fusions in a large percentage of cases (still other cases are positive for BRAF V600E mutation) [11]. It is noteworthy that many of the histological features described by Bielle et al. [3] in the adult high-grade gliomas with FGFR fusion, such as uniformly small rounded nuclei with conspicuous perinuclear halo, perivascular pseudorosetting, nuclear palisading and calcifications, are also seen in PLNTY, although these are exclusively low-grade tumors [11]. Finally, it is important to realize that FGFR fusions are not exclusive to the central nervous system tumors since FGFR3-TACC 3 fusions have been found in nonCNS malignancies including urothelial, breast, endometrial lung and ovarian cancers [10].

We noted that no study has undertaken a direct analysis of the histologic features of FGFR-fused CNS tumors in the pediatric population. The purpose of this study is to, for the first time, directly compare histological features of pediatric tumors with FGFR fusions and ask whether identification of these histological features might predict which tumors would show the highest yield in terms of identification of fusions and thus allow for triaging of cases for molecular testing of the fusion status, since such testing can be costly, time consuming, and may require send out to a reference laboratory.

\section{Material and methods}

We identified CNS tumors with FGFR gene alteration via a retrospective database review of all pediatric patients in the Department of Pathology databases at Children's Hospital Colorado, 2010-present. Fusion testing became available at our institution in 2016; however, some older cases underwent testing at the clinical team's request. For the vast majority of cases (9 out of 10 cases), the initial surgery and subsequent management had been performed at our institution. One case had been biopsied at outside institutions and reviewed at our department for diagnostic consultation. Standard H\&E stained sections were examined and the WHO 2016 classification of central nervous system tumors criteria were applied for all diagnoses, with the exception of PLNTY, which followed the diagnostic criteria outlined by Huse et al. [11].
Table I. List of genes tested in ArcherDx FusionPlex Solid Tumor Panel

\begin{tabular}{|cccc|}
\hline AKT3 & EWSR1 & NOTCH1 & PRKCA \\
\hline ALK & FGFR1 & NOTCH2 & PRKCB \\
\hline ARHGAP26 & FGFR2 & NRG1 & RAF1 \\
\hline AXL & FGFR3 & NTRK1 & RELA \\
\hline BRAF & FGR & NTRK2 & RET \\
\hline BRD3 & INSR & NTRK3 & ROS1 \\
\hline BRD4 & MAML2 & NUMBL & RSPO2 \\
\hline EGFR & MAST1 & NUTM1 & RSPO3 \\
\hline ERG & MAST2 & PDGFRA & TERT \\
\hline ESR1 & MET & PDGFRB & TFE3 \\
\hline ETV1 & MSMB & PIK3CA & TFEB \\
\hline ETV4 & MUSK & PKN1 & THADA \\
\hline ETV5 & MYB & PPARG & TMPRSS2 \\
\hline ETV6 & & \\
\hline
\end{tabular}

The Archer assay includes gene-specific primers to various exons (and some introns) in the above 53 genes and simultaneously detects and identifies fusions and other mutations associated with the listed genes.

Fusion testing was performed by the Colorado Molecular Correlates (CMOCO) Laboratory in the Department of Pathology at the University of Colorado Denver (UCD). Extracted nucleic acid samples were assessed using the ArcherDx FusionPlex (ArcherDx, Boulder, CO) Solid Tumor library preparation kit followed by sequencing on the Illumina platform $[8,13]$. This assay uses proprietary Anchored Multiplex PCR (AMP)-based library preparation to detect oncogenic gene isoforms and gene fusions regardless of the identity of the fusion partner. All cases were also tested on ArcherDx VariantPlex (ArcherDx, Boulder, CO) solid tumor panel which tests for mutations in 69 genes, including IDHI and IDH2. A complete list of genes covered on the fusion and mutational assay has been published previously [8] and provided as Tables I and II.

Clinical data for all cases were collected by review of the patient's electronic medical records on EPIC (Epic Systems Corporation, Verona, WI) and included the age, sex, clinical presentation, pre and post-surgical imaging findings, tumor location, extent of surgical resection, treatment modalities used, and survival.

\section{Results}

Ten cases of pediatric/young adult (less than 21 years of age) CNS tumors with FGFR alterations were identified. Of these cases, 6 involved FGFR1 fusions or tyrosine kinase domain (TKD) duplica- 
Table II. List of genes tested in ArcherDx VariantPlex Solid Tumor Panel

\begin{tabular}{|cccc|}
\hline$A B L 1$ & AKT1 & ALK & APC \\
\hline$A R$ & ATM & AURKA & BRAF \\
\hline CCND1 & CCNE1 & CDH1 & CDK4 \\
\hline CDKN2A & CDKN2B & CSF1R & CTNNB1 \\
\hline DDR2 & EGFR & ERBB2 & ERBB3 \\
\hline ERBB4 & ESR1 & EZH2 & FBXW7 \\
\hline FGFR1 & FGFR2 & FGFR3 & FLT3 \\
\hline FOXL2 & GNA11 & GNAQ & GNAS \\
\hline H3F3A & HNF1A & HRAS & IDH1 \\
\hline IDH2 & JAK2 & JAK3 & KDR \\
\hline KIT & KRAS & MAP2K1 & MDM2 \\
\hline MET & MLH1 & MPL & MYC \\
\hline MYCN & NOTCH1 & NPM1 & NRAS \\
\hline PDGFRA & PIK3CA & PIK3R1 & POLE \\
\hline PTEN & PTPN11 & RB1 & RET \\
\hline RHOA & ROS1 & SMAD4 & SMARCB1 \\
\hline SMOSRC & STK11 & TERT & TP53 \\
\hline VHL & & & \\
\hline
\end{tabular}

tions, 1 pediatric patient had FGFR2 fusion and 3 cases involved FGFR3 gene alterations. Fusion partners of FGFR genes included TACC1, TACC3, KIAA1598, THAP1O and INA genes. Clinicopathologic findings and fusion events are summarized in Table III.

CNS tumors with FGFR fusions were negative for co-occurring fusion or mutation events tested on our panels.

The pediatric CNS tumors harboring FGFR fusions in our cohort possessed more diverse histologic and molecular features than those reported for adult high-grade gliomas with tumors. In addition to the 3 FGFR3 fusion cases (with 3 different fusion partners, namely: TACC3, INA or THAP10), 6 cases of FGFR1 structural alterations (3 with FGFR1:TACC1 fusion, and 3 with TKD alterations) and 1 case of FGFR2:KIAA1598 were found. These findings are summarized in Table III. Histologic and radiologic features were similarly varied with cases carrying histologic diagnoses of extra ventricular neurocytoma $(n=1)$, pilomyxoid astrocytoma $(n=2)$, pilocytic astrocytoma $(n=1)$, PLNTY $(n=2)$, diffuse astrocytoma $(n=1)$, pediatric-type oligodendroglioma $(n=1)$, anaplastic astrocytoma with Li Fraumeni syndrome (LFS) $(n=1)$ and rosette-forming glioneuronal tumor $(n=1)$ (Table III). In contrast to the adult cases with FGFR fusions, all of which are reported to be GBM, IDH-wildtype, WHO grade IV [3], 9/10 pediatric cases showed low-grade glioma/glioneuronal histology, with one showing anaplastic astrocytoma histology (Table III).

Despite the diversity in histologic diagnosis, there were unifying features. Pediatric cases in our cohort showed frequent nuclear palisading (Fig. 1A-C), small monomorphic round cells (Fig. 1D-F), frequent calcifications (Fig. 2A-C), thin vasculature (Fig. 2D-F), and a low-grade histology without mitotic figures or elevated MIB-1 (Ki-67) staining (except in case 9, an anaplastic astrocytoma in LFS).

Retrospective review of the histologic features showed four distinct histologic groups as described below.

The first group ( $n=3$ ) showed pilocytic or pilomyxoid histology with tumor cells manifesting round to oval nuclei and long fibrillary/piloid processes, prominent perivascular arrangement was seen in two cases with absence of Rosenthal fibers or EGBs hence resembling pilomyxoid astrocytoma (Fig. 1A,B) - and one case was negative for perivascular tumor cell arrangement and positive for Rosenthal fibers (Fig. 1D) - hence consistent with pilocytic astrocytoma. While 2 of these cases showed no recurrence, case 3 with an FGFR1 exon 18:10 fusion has died of disease. In this case, the resection was incomplete owing to the presence of the tumor in an eloquent region (suprasellar/hypothalamic) and the surgery being complicated by parenchymal hemorrhage and brain damage. Whether the poor outcome was due to the FGFR 1 exon 18:10 fusion or the sensitive location/incomplete surgical resection remains unclear.

The second group $(n=2)$ consisted of glioneuronal tumors with extensive Cluster of Differentiation 34 (CD34) staining. Both of these cases had small round oligodendroglia-like cells with thin arcuate blood vessels (Figs. 1E, 2A), microcalcifications (Fig. 2A, arrow), and patchy strong CD34 staining, features that are suggestive of PLNTY (Fig. 1E, inset). One of these cases showed FGFR3:TACC3 and the other FGFR2:KIAA1598 fusion, similar to what has been previously reported for PLNTY [11]. None of these cases has shown a recurrence in 9-13 months of post-resection follow up.

The third group $(n=3)$ showed an infiltrative histology (Figs. 1F, 2C-E). These cases had round or oval oligodendrocyte-like or astrocytic cells with variable perinuclear halos (Fig. 1F, 2C, D) and thin arcuate vasculature (Fig. 2D) with one case additionally showing calcifications (Fig. 2C, arrow). Unlike group 2, no CD34 staining was seen in these cases, ruling out PLNTY. 
Table III. Clinical and pathologic features of patients with central nervous system (CNS) tumors harboring FGFR structural alterations

\begin{tabular}{|c|c|c|c|c|c|c|c|}
\hline Case \# & $\begin{array}{l}\text { Age } \\
\text { (yrs) }\end{array}$ & Sex & $\begin{array}{l}\text { Molecular } \\
\text { findings }\end{array}$ & $\begin{array}{l}\text { Imaging } \\
\text { findings }\end{array}$ & $\begin{array}{l}\text { Histologic } \\
\text { diagnosis }\end{array}$ & $\begin{array}{l}\text { Clinical } \\
\text { follow up }\end{array}$ & $\begin{array}{l}\text { Follow up } \\
\text { interval }\end{array}$ \\
\hline Case 1 & 1 & $\mathrm{~F}$ & $\begin{array}{l}\text { FGFR1 exon 19:10 } \\
\text { repeat }\end{array}$ & $\begin{array}{c}\text { Diffusely } \\
\text { infiltrating tumor involving } \\
\text { bilateral basal ganglia, } \\
\text { optic pathways, } \\
\text { septum pellucidum, } \\
\text { medial left temporal lobe, } \\
\text { and brainstem }\end{array}$ & $\begin{array}{c}\text { Diffuse } \\
\text { astrocytoma }\end{array}$ & $\begin{array}{l}\text { Died of disease, } \\
\text { rapid progression } \\
\text { of invasive tumor }\end{array}$ & 15 mth \\
\hline Case 2 & 1 & M & FGFR1:TACC1 & $\begin{array}{l}\text { Solid and cystic cervical } \\
\text { spinal cord tumor }\end{array}$ & $\begin{array}{l}\text { Pilomyxoid } \\
\text { astrocytoma }\end{array}$ & $\begin{array}{l}\text { Negative for tumor } \\
\text { recurrence }\end{array}$ & 3 yrs \\
\hline Case 3 & 2 & $\mathrm{~F}$ & FGFR1 exon 18:10 & $\begin{array}{l}\text { Large suprasellar/ } \\
\text { hypothalamic mass } \\
\text { extending into the } \\
\text { right frontal lobe, third } \\
\text { ventricle, interpeduncular } \\
\text { and prepontine } \\
\text { cistern }\end{array}$ & $\begin{array}{l}\text { Pilomyxoid } \\
\text { astrocytoma }\end{array}$ & $\begin{array}{l}\text { Died of disease; } \\
\text { incomplete resection } \\
\text { of tumor followed } \\
\text { by intratumoral } \\
\text { and parenchymal } \\
\text { hemorrhage and } \\
\text { subsequent brain } \\
\text { damage }\end{array}$ & 9 mth \\
\hline Case 4 & 4 & M & $\begin{array}{l}\text { FGFR1 exon 19:10 } \\
\text { repeat }\end{array}$ & $\begin{array}{l}\text { Left thalamic tumor } \\
\text { extending into internal } \\
\text { capsule, caudate, globus } \\
\text { pallidus, midbrain and the } \\
\text { medial left temporal lobe }\end{array}$ & $\begin{array}{c}\text { Pediatric-type } \\
\text { oligodendroglioma }\end{array}$ & $\begin{array}{l}\text { Died of disease, } \\
\text { progressive interval } \\
\text { growth of tumor }\end{array}$ & 24 mth \\
\hline Case 5 & 6 & $\mathrm{~F}$ & FGFR2:KIAA1598 & $\begin{array}{c}\text { Right insular cortex cystic } \\
\text { and solid mass with } \\
\text { haziness to the subjacent } \\
\text { white matter }\end{array}$ & PLNTY & No residual tumor & $13 \mathrm{mth}$ \\
\hline Case 6 & 9 & M & $\begin{array}{l}\text { FGFR1: } \\
\text { TACC1 }\end{array}$ & $\begin{array}{c}\text { Acute bleeding at } \\
\text { presentation with } \\
\text { hyperdense mass of } \\
\text { posterior temporal lobe }\end{array}$ & $\begin{array}{l}\text { Extraventricular } \\
\text { neurocytoma }\end{array}$ & $\begin{array}{l}\text { Negative for tumor } \\
\text { recurrence }\end{array}$ & $25 \mathrm{mth}$ \\
\hline Case 7 & 11 & $\mathrm{~F}$ & FGFR3:TACC3 & $\begin{array}{c}\text { Medial right temporal lobe } \\
\text { heterogeneous mass with } \\
\text { numerous small cystic } \\
\text { components }\end{array}$ & PLNTY & $\begin{array}{l}\text { Negative for tumor } \\
\text { recurrence }\end{array}$ & 9 mth \\
\hline Case 8 & 16 & $\mathrm{~F}$ & $\begin{array}{l}\text { FGFR1: } \\
\text { TACC1 }\end{array}$ & $\begin{array}{l}\text { Midbrain, dorsal } \\
\text { tegmentum and tectum } \\
\text { non-enhancing mass }\end{array}$ & $\begin{array}{c}\text { Pilocytic } \\
\text { astrocytoma }\end{array}$ & $\begin{array}{l}\text { Negative for tumor } \\
\text { recurrence }\end{array}$ & $26 \mathrm{mth}$ \\
\hline Case 9 & 19 & M & FGFR3:INA & $\begin{array}{l}\text { Right frontal lobe non- } \\
\text { enhancing lesion with } \\
\text { interval growth first } \\
\text { identified on screening } \\
\text { MRI }\end{array}$ & $\begin{array}{c}\text { Anaplastic } \\
\text { astrocytoma in LFS }\end{array}$ & $\begin{array}{l}\text { Negative for tumor } \\
\text { recurrence }\end{array}$ & $7 \mathrm{yrs}$ \\
\hline Case 10 & 21 & $\mathrm{~F}$ & FGFR3:THAP10 & $\begin{array}{c}\text { Intraventricular mass, } \\
\text { right frontal horn of lateral } \\
\text { ventricle }\end{array}$ & $\begin{array}{l}\text { Rosette-forming } \\
\text { glioneuronal tumor }\end{array}$ & $\begin{array}{l}\text { Negative for tumor } \\
\text { recurrence }\end{array}$ & 8 yrs \\
\hline
\end{tabular}

mth-months, yrs - years, PLNTY - polymorphous low-grade neuroepithelial tumor of the young, LFS - Li Fraumeni syndrome

Two of these cases showed FGFR1 exon 19:10 repeat fusion and one showed FGFR3:INA fusion; all were IDH1/2 wildtype (tested by IHC as well as mutational analysis) and negative for $1 \mathrm{p} / 19 \mathrm{q}$ codeletion (tested by FISH). One of these cases (case 9) occurred in the context of known history of Li-Fraumeni syndrome and had frankly anaplastic histology. The third case in this group was diagnosed as a pediatric-type oligodendroglioma and was confirmed to be IDH-wildtype without $1 p / 19 q$ codeletion. 

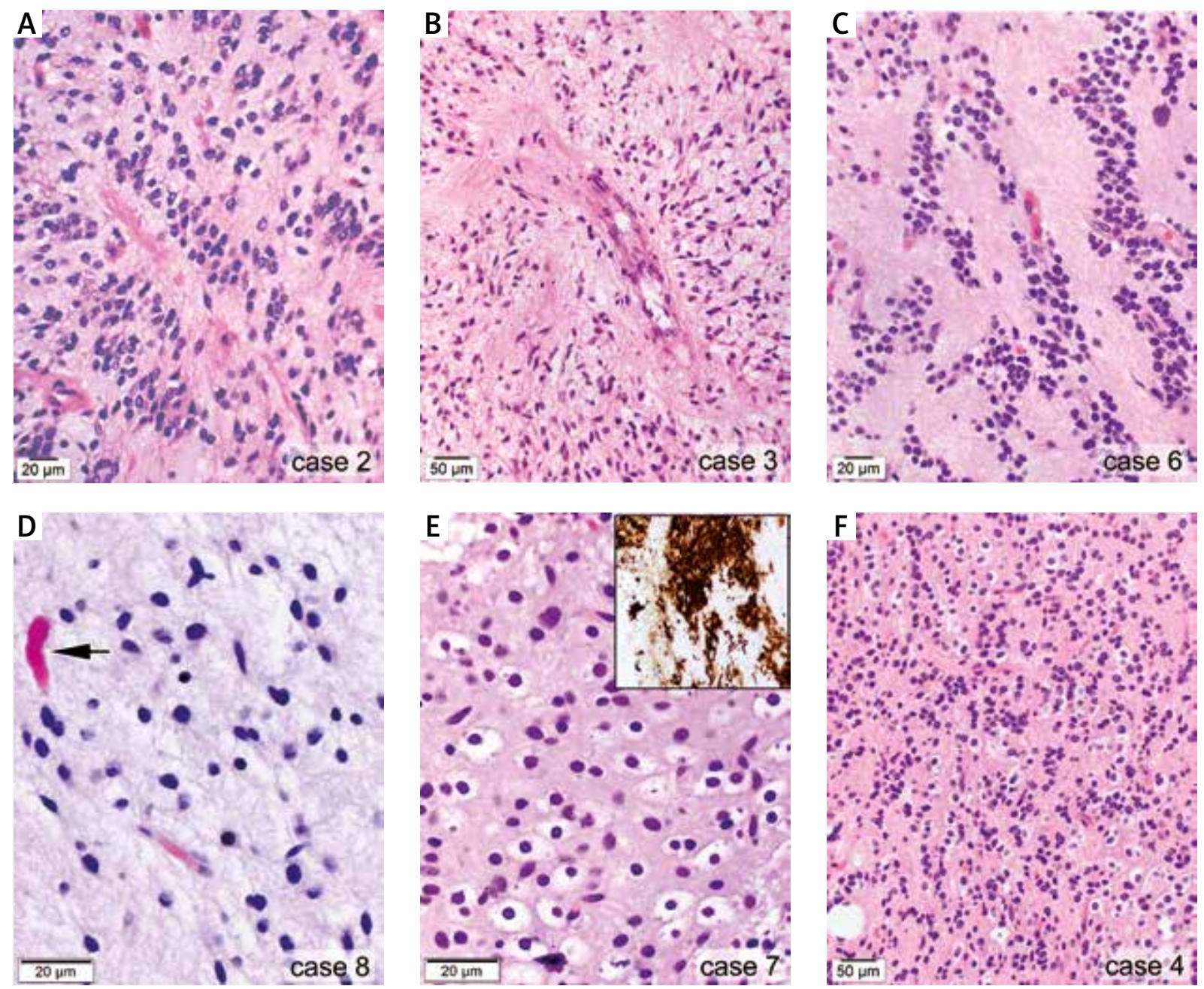

Fig. 1. FGFR altered pediatric central nervous system (CNS) tumors show monomorphic round cells and nuclear clustering: despite histologic variability, majority of cases showed monomorphic round cells and nuclear clustering. A-C) 6 cases with histologic diagnoses of pilomyxoid astrocytoma (A, B), extraventricular neurocytoma (C), pilocytic astrocytoma (D), PLNTY (E) and pediatric-type oligodendroglioma (F) all showing tumor cells with small round monomorphic nuclei. Nuclear palisading/clustering and perivascular arrangement in tumors with histologic diagnoses varying from pilomyxoid astrocytoma (A-B) and extraventricular neurocytoma (C). D) Arrow highlights a Rosenthal fiber. E) Inset shows patchy strong CD34 staining supporting the diagnosis of PLNTY.

Finally, the last group consisted of unique cases $(n=2)$. One case showed neurocytic rosettes with small round $(\mathrm{NeuN}+)$ cells arranged around neurocytic rosettes (Figs. 1C, 2F) and surrounded by microcalcification (Fig. 2B). This case showed FGFR 1:TACC 1 fusion and was diagnosed as extra ventricular neurocytoma. The last case (case 10) was consistent with rosette-forming glioneuronal tumor.

It is not clear whether FGFR fusion status effects prognosis in tumors independent of histologic features [18]. Anecdotally, however, we do note that in our small cohort of 10 pediatric examples, 3 patients with FGFR 1:exon 18 or exon 19 fusions, involving the thalamus, hypothalamus and basal ganglia, died of disease (cases 1, 3 and 4), while the rest are free of disease (Table III). Whether this is due to the surgically sensitive/eloquent nature of midline tumors or the presence of the FGFR 1:exon 18 or exon 19 fusion is unclear.

In summary, most but not all FGFR fused tumors in the pediatric population show at least some characteristic histologic features including small mono- 

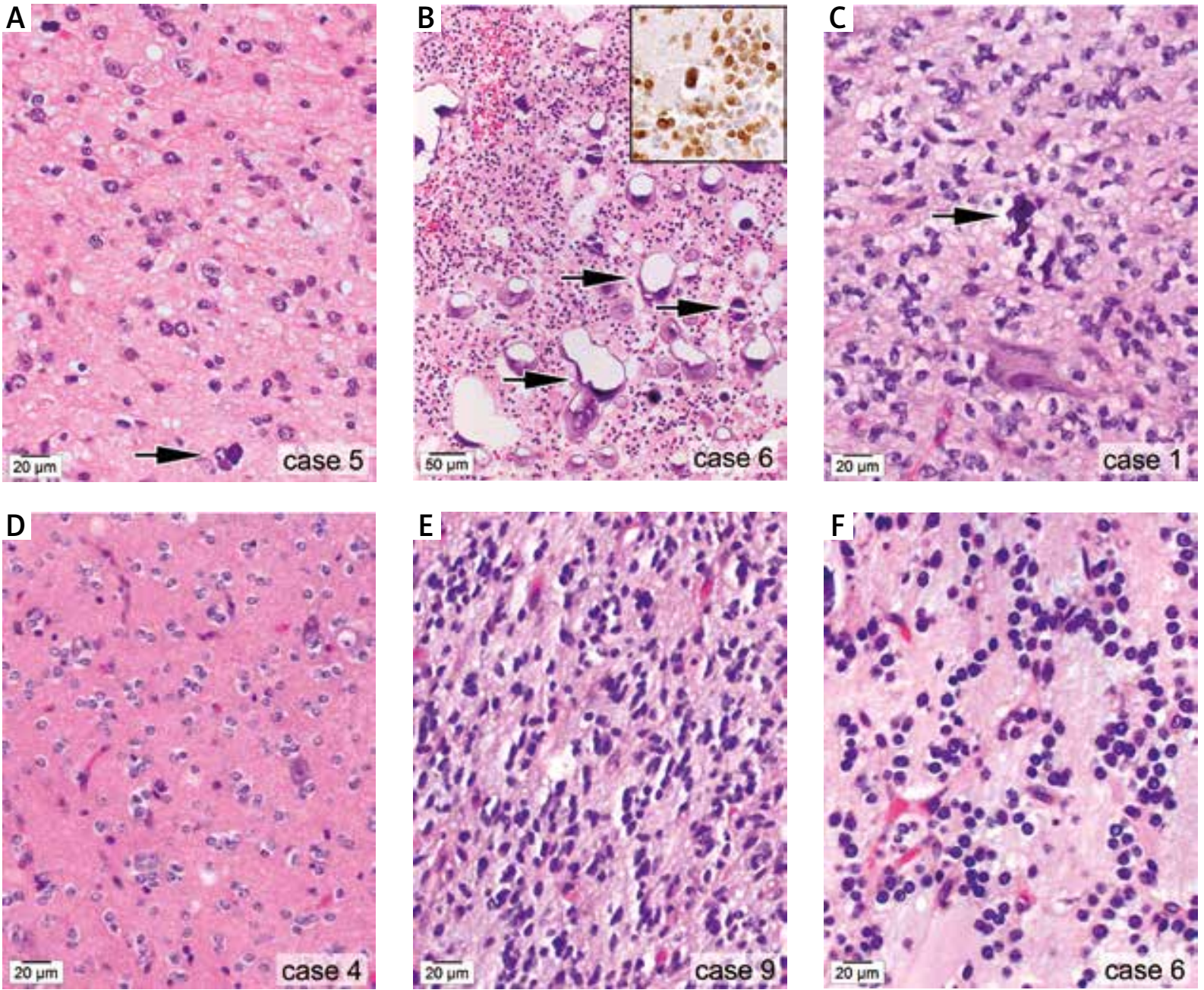

Fig. 2. FGFR altered pediatric central nervous system (CNS) tumors show frequent microcalcifications and delicate arcuate vasculature: A-C) Microcalcifications (arrows) were frequently seen in cases diagnosed as PLNTY (A), extraventricular neurocytoma (B), diffuse astrocytoma (C). Inset in panel B shows NeuN staining confirming the neurocytic differentiation in the extraventricular neurocytoma. D-F) thin delicate arcuate capillary network in cases with histologic diagnosis of pediatric-type oligodendroglioma (D), anaplastic astrocytoma in LFS (E) and extraventricular neurocytoma (F). D) Note the large entrapped neurons with normal cytological appearance and even placement of Nissl substance, excluding consideration of ganglioglioma.

morphic cells, fine arcuate vasculature, and microcalcification, histologic features that are reported for adult high-grade gliomas with FGFR3:TACC3 fusion.

\section{Discussion}

In this study, we report the histological features of pediatric CNS tumors with FGFR fusion, adding to the growing literature that these are mostly lowgrade glial and glioneuronal tumors. We determine that although the histological features reported by Bielle et al. [3] in adult IDH-wildtype GBMs are pres- ent to some degree in pediatric tumors, they are far from uniform and not archetypal enough to allow histological prediction of the fusion for adult gliomas and especially not for pediatric CNS tumors.

Pediatric CNS tumors with FGFR fusions, in contrast to adult high-grade gliomas with this fusion [3], are a more histologically and molecularly heterogeneous cohort, as we and others $[4,13]$ have shown. Thus, the fusion status is more difficult to predict, although certain histological features shared with their FGFR-fused adult counterparts do exist that 
can aid in prompting molecular testing. In contrast to adult examples with this fusion [3], pediatric examples have almost exclusively been low-grade, yet, as we have demonstrated, still share overlapping morphological features of monomorphic nuclei, microcalcifications, nuclear palisading, and arcuate vasculature. These features are shared by several types of low-grade tumors and thus result in more diverse diagnoses, such as diffuse astrocytoma, anaplastic astrocytoma, pilocytic and pilomyxoid astrocytoma, PLNTY, neurocytoma, and rosette-forming glioneuronal tumor.

Thus, in pediatric tumors, while we show that FGFR fusions can be suspected based on these histological features in a variety of different WHO 2016 diagnoses, nevertheless, fusion testing is recommended in all pediatric tumors, given the possibility of identifying therapeutically targetable alterations in this age group in order to eschew use of more toxic chemo- and radiotherapies [13]. Of note, while the tumor types in our cohort were mostly lowgrade and thus more aggressive therapies are often not necessary initially after first resection, unfavorable anatomical location may lead to the inability to achieve significant surgical resection and continued tumor growth may contribute to progressive symptomatology at a later time period. Often, some therapy becomes necessary during the course of the disease. Thus, similar to our work with gangliogliomas of the brainstem with BRAF V600E mutation, making them amenable to targeted therapy [6], the situation may arise that targeted therapy is also necessary in FGFR fusion-bearing low-grade pediatric tumors in unfavorable anatomical locations. Indeed, although the number of cases in our study is small, we did observe anecdotally that the only deaths in our cohort of 10 pediatric patients were in those tumors that were located in unfavorable/eloquent anatomical locations (Table III).

Within our cohort, the fusions we encountered parallel those in the literature, as reviewed by Bale [1]. Specifically, the cases of PLNTY showed FGFR3TACC3 or FGFR2-KIAA1598 fusion. Both of these fusions (in addition to cases showing FGFR2-CTNNA3 fusion or BRAF V600E mutation) have been reported previously in PLNTY [11]. The extraventricular neurocytoma similarly showed FGFR1:TACC1 fusion which is the most common alteration reported in this tumor [22]. Finally, the single case of rosette-forming glioneuronal tumor in our cohort showed FGFR3:THAP10 fusion. It is noteworthy that the largest case series of this rare tumor reported FGFR 1 hotspot mutations in all cases with a majority exhibiting co-occurring PIK3CA and/or NF1 gene mutations [20]. Given the similarities between FGFR1 and FGFR3 genes and a shared downstream signaling pathway, our findings are consistent with those of Sievers and colleagues showing activation of mitogen-activated protein kinase (MAPK) pathway in this tumor [20]. We further note that FGFR fusions in our study occurred in the absence of any other identifiable fusion or mutation events (for a complete list of genes tested, see Tables I and II).

A recent paper, published during the preparation of this manuscript, shows that the presence of FGFR alterations, mostly FGFR1-TACC1 fusion, in pediatric posterior fossa pilocytic astrocytomas correlate with oligodendroglial morphology, namely small monomorphic cells with round and partly hyperchromatic nuclei, perivascular halos, and calcifications [21]. This and other studies suggest the presence of shared histologic features in FGFR-fused tumors.

A major limitation, that might be a consideration, is that this is a single institution study with a relatively small sample size. For each type of FGFR alteration, a single or a small set of cases is included. Conversely, however, multi-institution studies looking at histomorphologic features can suffer from inter-observer bias. Hence, one of the strengths of this study is that all cases were diagnosed at a single institution and are more likely to be homogeneous in interpretation of histologic features.

We conclude that while pediatric tumors with FGFR fusions do show monomorphic oligodendroglia-like nuclei, arcuate vasculature, and microcalcifications, similar to those described by Bielle et al. in adult tumors, the features are too variable in extent to histologically predict the presence of fusion in pediatric tumors since the FGFR-fusion positive group comprises so many different diagnostic entities, including but not limited to pilocytic astrocytoma, pilomyxoid astrocytoma, PLNTY, extraventricular neurocytoma, rosette forming glioneuronal tumor, and pediatric-type oligodendroglioma.

Our final conclusion is that broad mutational and fusion testing remains necessary for pediatric patients with any glioneuronal CNS tumor, despite the cost and time burdens. We therefore recommend that fusion testing be performed for all pediatric glioneuronal tumors, regardless of histological 
features; unfortunately, histological triaging of cases will miss examples with this potentially targetable fusion.

\section{Acknowledgements}

This work was supported by the Molecular Pathology Shared Resource of the University of Colorado (National Cancer Institute Cancer Center Support Grant No. P30-CA046934). We thank Lisa Litzenberger for assistance with the figures and Jennifer Platte with editorial assistance.

\section{Disclosure}

KDD has received sponsored travel from ArcherDx. All other authors have no conflict of interest to declare. All procedures performed in studies involving human participants were in accordance with the ethical standards of the institutional research board (IRB \# 95-500) and with the 1964 Helsinki declaration and its later amendments or comparable ethical standards. This article does not contain any studies with animals performed by any of the authors.

\section{References}

1. Bale TA. FGFR-gene family alterations in low-grade neuroepithelial tumors. Acta Neuropathol Commun 2020; 8: 21.

2. Ballester LY, Moghadamtousi SZ, Leeds NE, Huse JT, Fuller GN. Coexisting FGFR3 p.K650T mutation in two FGFR3-TACC3 fusion glioma cases. Acta Neuropathol Commun 2019; 7: 63.

3. Bielle F, Di Stefano AL, Meyronet D, Picca A, Villa C, Bernier M, Schmitt Y, Giry M, Rousseau A, Figarella-Branger D, Maurage CA, Uro-Coste E, Lasorella A, lavarone A, Sanson M, Mokhtari K. Diffuse gliomas with FGFR3-TACC3 fusion have characteristic histopathological and molecular features. Brain Pathol 2018; 28: 674-683.

4. Cole B, Lockwood C, Paulson V, Leary S. Gene-21. Pediatric brain tumors with FGFR1 mutations: a series of 14 cases assessing the morphologic spectrum and associated genetic alterations. Neuro Oncol 2019; 21: ii85-ii86.

5. Di Stefano AL, Fucci A, Frattini V, Labussiere M, Mokhtari K, Zoppoli P, Marie Y, Bruno A, Boisselier B, Giry M, Savatovsky J, Touat M, Belaid H, Kamoun A, Idbaih A, Houillier C, Luo FR, Soria JC, Tabernero J, Eoli M, Paterra R, Yip S, Petrecca K, Chan JA, Finocchiaro G, Lasorella A, Sanson M, lavarone A. Detection, characterization, and inhibition of FGFR-TACC fusions in IDH wild-type glioma. Clin Cancer Res 2015; 21: 3307-3317.

6. Donson AM, Kleinschmidt-DeMasters BK, Aisner DL, Bemis LT, Birks DK, Levy JM, Smith AA, Handler MH, Foreman NK, Rush SZ. Pediatric brainstem gangliogliomas show BRAF(V600E) mutation in a high percentage of cases. Brain Pathol 2014; 24: 173-183.

7. Ellison DW, Hawkins C, Jones DTW, Onar-Thomas A, Pfister SM, Reifenberger G, Louis DN. CIMPACT-NOW update 4: diffuse gliomas characterized by MYB, MYBL1, or FGFR1 alterations or BRAF(V600E) mutation. Acta Neuropathol 2019; 137: 683-687.

8. Gilani A, Donson A, Davies KD, Whiteway SL, Lake J, DeSisto J, Hoffman L, Foreman NK, Kleinschmidt-DeMasters BK, Green AL. Targetable molecular alterations in congenital glioblastoma. J Neurooncol 2020; 146: 247-252.

9. Granberg KJ, Annala M, Lehtinen B, Kesseli J, Haapasalo J, Ruusuvuori P, Yli-Harja O, Visakorpi T, Haapasalo H, Nykter M, Zhang W. Strong FGFR3 staining is a marker for FGFR3 fusions in diffuse gliomas. Neuro Oncol 2017; 19: 1206-1216.

10. Helsten T, Elkin S, Arthur E, Tomson BN, Carter J, Kurzrock R. The FGFR landscape in cancer: analysis of 4,853 tumors by next-generation sequencing. Clin Cancer Res 2016; 22: 259-267.

11. Huse JT, Snuderl M, Jones DTW, Brathwaite CD, Altman N, Lavi E, Saffery R, Sexton-Oates A, Blumcke I, Capper D, Karajannis MA, Benayed R, Chavez L, Thomas C, Serrano J, Borsu L, Ladanyi M, Rosenblum MK. Polymorphous low-grade neuroepithelial tumor of the young (PLNTY): an epileptogenic neoplasm with oligodendroglioma-like components, aberrant CD34 expression, and genetic alterations involving the MAP kinase pathway. Acta Neuropathol 2017; 133: 417-429.

12. Jones DT, Hutter B, Jäger N, Korshunov A, Kool M, Warnatz HJ, Zichner T, Lambert SR, Ryzhova M, Quang DA, Fontebasso AM, Stütz AM, Hutter S, Zuckermann M, Sturm D, Gronych J, Lasitschka B, Schmidt S, Seker-Cin H, Witt H, Sultan M, Ralser M, Northcott PA, Hovestadt V, Bender S, Pfaff E, Stark S, Faury D, Schwartzentruber J, Majewski J, Weber UD, Zapatka M, Raeder B, Schlesner M, Worth CL, Bartholomae CC, von Kalle C, Imbusch CD, Radomski S, Lawerenz C, van Sluis P, Koster J, Volckmann R, Versteeg R, Lehrach H, Monoranu C, Winkler B, Unterberg A, Herold-Mende C, Milde T, Kulozik AE, Ebinger M, Schuhann MU, Cho YJ, Pomeroy SL, von Deimling A, Witt O, Taylor MD, Wolf S, Karajannis MA, Eberhart CG, Scheurlen W, Hasselblatt M, Ligon KL, Kieran MW, Korbel JO, Yaspo ML, Brors B, Felsberg J, Reifenberger G, Collins VP, Jabado N, Eils R, Lichter P, Pfister SM. Recurrent somatic alterations of FGFR1 and NTRK2 in pilocytic astrocytoma. Nat Genet 2013; 45: 927-932.

13. Lake J, Donson AM, Prince E, Davies KD, Nellan A, Green AL, Mulcahy Levy J, Dorris K, Vibhakar R, Hankinson TC, Foreman NK, Ewalt MD, Kleinschmidt-DeMasters BK, Hoffman LM, Gilani A. Targeted fusion analysis can aid in the classification and treatment of pediatric glioma, ependymoma, and glioneuronal tumors. Pediatr Blood Cancer 2020; 67: e28028.

14. Louis DN, Perry A, Reifenberger G, von Deimling A, FigarellaBranger D, Cavenee WK, Ohgaki H, Wiestler OD, Kleihues P, Ellison DW. The 2016 World Health Organization Classification of Tumors of the Central Nervous System: a summary. Acta Neuropathol 2016; 131: 803-820.

15. Nelson KN, Meyer AN, Siari A, Campos AR, Motamedchaboki K, Donoghue DJ. Oncogenic gene fusion FGFR3-TACC3 is regulated by tyrosine phosphorylation. Mol Cancer Res 2016; 14: 458-469.

16. Pathak P, Kumar A, Jha P, Purkait S, Faruq M, Suri A, Suri V, Sharma MC, Sarkar C. Genetic alterations related to BRAF-FGFR genes and dysregulated MAPK/ERK/mTOR signaling in adult pilocytic astrocytoma. Brain Pathol 2017; 27: 580-589. 
17. Qaddoumi I, Orisme W, Wen J, Santiago T, Gupta K, Dalton JD, Tang B, Haupfear K, Punchihewa C, Easton J, Mulder H, Boggs K, Shao Y, Rusch M, Becksfort J, Gupta P, Wang S, Lee RP, Brat D, Peter Collins V, Dahiya S, George D, Konomos W, Kurian KM, McFadden K, Serafini LN, Nickols H, Perry A, Shurtleff S, Gajjar A, Boop FA, Klimo PD Jr, Mardis ER, Wilson RK, Baker SJ, Zhang J, Wu G, Downing JR, Tatevossian RG, Ellison DW. Genetic alterations in uncommon low-grade neuroepithelial tumors: BRAF, FGFR1, and MYB mutations occur at high frequency and align with morphology. Acta Neuropathol 2016; 131: 833-845.

18. Ryall S, Zapotocky M, Fukuoka K, Nobre L, Guerreiro Stucklin A, Bennett J, Siddaway R, Li C, Pajovic S, Arnoldo A, Kowalski PE, Johnson M, Sheth J, Lassaletta A, Tatevossian RG, Orisme W, Qaddoumi I, Surrey LF, Li MM, Waanders AJ, Gilheeney S, Rosenblum M, Bale T, Tsang DS, Laperriere N, Kulkarni A, Ibrahim GM, Drake J, Dirks P, Taylor MD, Rutka JT, Laughlin S, Shroff M, Shago M, Hazrati L-N, D’Arcy C, Ramaswamy V, Bartels U, Huang A, Bouffet E, Karajannis MA, Santi M, Ellison DW, Tabori $U$, Hawkins C. Integrated molecular and clinical analysis of 1,000 pediatric low-grade gliomas. Cancer Cell 2020; 37: 569683.e5.

19. Singh D, Chan JM, Zoppoli P, Niola F, Sullivan R, Castano A, Liu EM, Reichel J, Porrati P, Pellegatta S, Qiu K, Gao Z, Ceccarelli M, Riccardi R, Brat DJ, Guha A, Aldape K, Golfinos JG, Zagzag D, Mikkelsen T, Finocchiaro G, Lasorella A, Rabadan R, lavarone A. Transforming fusions of FGFR and TACC genes in human glioblastoma. Science 2012; 337: 1231-1235.

20. Sievers P, Appay R, Schrimpf D, Stichel D, Reuss DE, Wefers AK, Reinhardt A, Coras R, Ruf VC, Schmid S, de Stricker K, Boldt HB, Kristensen BW, Petersen JK, Ulhøi BP, Gardberg M, Aronica E, Hasselblatt M, Brück W, Bielle F, Mokhtari K, Lhermitte B, Wick W, Herold-Mende C, Hänggi D, Brandner S, Giangaspero F, Capper D, Rushing E, Wesseling P, Pfister SM, FigarellaBranger D, von Deimling A, Sahm F, Jones DTW. Rosette-forming glioneuronal tumors share a distinct DNA methylation profile and mutations in FGFR1, with recurrent co-mutation of PIK3CA and NF1. Acta Neuropathol 2019; 138: 497-504.

21. Sievers P, Schrimpf D, Stichel D, Reuss DE, Hasselblatt M, Hagel C, Staszewski O, Hench J, Frank S, Brandner S, Korshunov A, Wick W, Pfister SM, Reifenberger G, von Deimling A, Sahm F, Jones DTW. Posterior fossa pilocytic astrocytomas with oligodendroglial features show frequent FGFR1 activation via fusion or mutation. Acta Neuropathol 2020; 139: 403-406.

22. Sievers P, Stichel D, Schrimpf D, Sahm F, Koelsche C, Reuss DE, Wefers AK, Reinhardt A, Huang K, Ebrahimi A, Hou Y, Pajtler KW, Pfister SM, Hasselblatt M, Stummer W, Schick U, Hartmann C, Hagel C, Staszewski O, Reifenberger G, Beschorner R, Coras R, Keyvani K, Kohlhof P, Diomedi-Camassei F, Herold-Mende C, Giangaspero F, Rushing E, Giannini C, Korshunov A, Jones DTW, von Deimling A. FGFR1:TACC1 fusion is a frequent event in molecularly defined extraventricular neurocytoma. Acta Neuropathol 2018; 136: 293-302.

23. Tanner Y, Grose RP. Dysregulated FGF signalling in neoplastic disorders. Semin Cell Dev Biol 2016; 53: 126-135. 